\title{
Low temperature specifications for asphalt binders: tests and simulation
}

\author{
Lucas Feitosa de A. L. Babadopulos ${ }^{1}$, Malo Le Guern², \\ Emmanuel Chailleux ${ }^{3}$ e Sylvia Dreessen ${ }^{4}$
}

\begin{abstract}
Resumo: Este trabalho apresenta uma comparação entre dois métodos de determinação de desempenho quanto à fissuração a baixa temperatura para asfaltos: 1) Bending Beam Rheometer (BBR), baseado na reologia do ligante e 2) alternativa baseada na mecânica da fratura utilizando-se um ensaio de flexão três pontos (F3P). A relação teórica entre elas foi analisada e testes foram simulados com o auxílio da teoria da viscoelasticidade linear. Dados de módulo complexo foram utilizados para se determinar uma série de Prony representando o comportamento mecânico dos materiais. Oito diferentes ligantes asfálticos e os materiais resultantes de envelhecimento em laboratório foram testados. O coeficiente de determinação $\left(\mathrm{R}^{2}\right)$ entre as temperaturas limite BBR simuladas e experimentais se situa entre 0,82 e 0,92 . Por meio do ensaio de F3P, calculou-se a tenacidade dos materiais e um segundo parâmetro, baseado no campo de deformação, foi proposto. Os critérios de ruptura puderam diferenciar o comportamento de fissuração a frio dos asfaltos. As classificações obtidas através dos dois métodos foram comparadas, de forma que o critério reológico e o baseado no ensaio de fratura ordenam ligantes diferentemente.
\end{abstract}

Palavras-chave: fissuração a baixa temperatura, viscoelasticidade linear, Bending Beam Rheometer, ensaio de flexão três pontos.

\begin{abstract}
This paper presents a comparison between two methods to determine low temperature crack performance for asphalt binders: 1) the Bending Beam Rheometer (BBR), which is a rheology-based method, and 2) alternative fracture mechanics-based criteria obtained using a three points bending test (TPBT). The theoretical relation between them was analyzed and tests were simulated using the theory of linear viscoelasticity. Complex modulus data were used to determine Prony series representing materials' mechanical behavior. Eight different asphalt binders and the materials resulting from their aging process in laboratory were tested. The determination coefficient $\left(\mathrm{R}^{2}\right)$ between the simulated BBR limit temperatures and the experimental ones was between 0.82 and 0.92 . For the TPBT the fracture toughness was determined and a deformation intensity factor was proposed. The fracture criteria could differentiate binder performance. The ranking obtained for the two methods was compared. The rheology-based and the fracture mechanics-based criteria rank asphalt binders differently.
\end{abstract}

Keywords: low temperature crack, linear viscoelasticity, Bending Beam Rheometer, three points bending test.

\section{INTRODUCTION}

Current European and American specifications for low temperature cracking resistance of asphalt binders are based on empirical tests (e. g. FRAASS test) or tests involving linear viscoelasticity (e. g. creep or complex modulus). However, although these standard criteria to differentiate low temperature cracking behavior may work for pure asphalt, they cannot be applied to all asphalt binders. For example, adding polymer (which has good compatibility with asphalt) gives a strong increase in binder's low temperature properties reproduced in field conditions, yet there is still poor variation in binder stiffness obtained by the Bending Beam Rheometer (BBR) tests in accordance with AASHTO T 313-02.

In this context, the standard criteria (temperature at which the material's secant modulus $-\mathrm{S}$ - equals $300 \mathrm{MPa}$ or temperature at which the creep rate $-\mathrm{m}$ - equals 0.3 ) cannot differentiate pure and modified asphalt binders,

${ }^{1}$ Lucas Feitosa de A. L. Babadopulos, Centre de Recherche de Solaize de TOTAL, France. (e-mail: lucasbaba@hotmail.com).

${ }^{2}$ Malo Le Guern, Laboratoire Central des Ponts et Chaussées, France. (email: malo.leguern@yahoo.fr).

${ }^{3}$ Emmanuel Chailleux, Laboratoire Central des Ponts et Chaussées, France. (e-mail: emmanuel.chailleux@ifsttar.fr).

${ }^{4}$ Sylvia Dreessen, Centre de Recherche de Solaize de TOTAL, France. (email: sylvia.dreessen@total.com).

Manuscrito recebido em 25/4/2011 e aprovado para publicação em 26/7/2011. Este artigo é parte de TRANSPORTES v.19, n.2, 2011. ISSN: 2237-1346

(online). prompting analysts to turn to a test based on the principles of fracture mechanics. For that, a fracture strength test (three points bending test - TPBT), which allows to work in localized large deformations, was adapted to asphalt binders and developed by Lee and Hesp (1994), Morrison et al. (1994) and Ponniah and Hesp (1996). Research by those authors shows that it is possible to better describe the cracking resistance of asphalt binders by obtaining intrinsic characteristics such as fracture toughness $\left(\mathrm{K}_{\mathrm{IC}}\right)$ or critical strain energy release rate $\left(\mathrm{G}_{\mathrm{IC}}\right)$. These researches have used linear elastic fracture mechanics principles, where the asphalt, at low temperature, is considered as a brittle, elastic material. However, while this assumption may well appear valid at very low temperatures (under $-20^{\circ} \mathrm{C}$ ), it is important to take into account asphalt viscoelasticity when higher temperatures (near $0^{\circ} \mathrm{C}$ ) are involved, especially during ductile-to-brittle transition.

The study reported here proposes to simulate BBR tests using data from complex modulus to obtain BBR critical temperatures using the theory of linear viscoelasticity. Also, this papers aims to introduce the concept of viscoelasticity in the analysis of TPBT by distinguishing stress intensity $\left(\mathrm{K}^{\sigma}\right)$ and crack opening $\left(\mathrm{K}^{\varepsilon}\right)$ factors. A procedure based on the finite element method is used to determine these two material properties obtained using the fracture mechanics theory and using data from TPBT on prenotched asphalt beams. In order to test the hypothesis that BBR critical temperatures can be obtained theoretically from complex modulus data and to compare BBR specifications with the proposed fracture mechanics criteria, differ- 
Table 1. Definition of the BBR indicators

\begin{tabular}{llll}
\hline Indicator : & $\begin{array}{l}\text { Iso-modulus Temperature } \\
\left(\boldsymbol{T}_{\mathbf{3 0 0 M P a}}\right)\end{array}$ & Slope $\boldsymbol{m}$ & Critical Temperature $\left(\boldsymbol{T}_{\text {Crit }}\right)$ \\
\hline & $\begin{array}{l}\text { Temperature for which the } \\
\text { measured stiffness after } 60 \mathrm{~s} \text { of }\end{array}$ & $\begin{array}{l}\text { Absolute logarithmic creep rate } \\
\text { (derivative of } \log (\mathrm{S}(\mathrm{t})) \mathrm{vs} . \mathrm{t}) \text { after }\end{array}$ & $\begin{array}{l}\text { Temperature at which the slope } \mathrm{m} \\
\text { is } 0,300(\mathrm{~S} \text { in } \mathrm{MPa}) \text { after } 60 \mathrm{~s} \text { of } \\
\text { loading }\end{array}$ \\
Definition : & loading equals $300 \mathrm{MPa}$ & 60s of loading at $\mathrm{T}_{300 \mathrm{MPa}}$ & loat
\end{tabular}

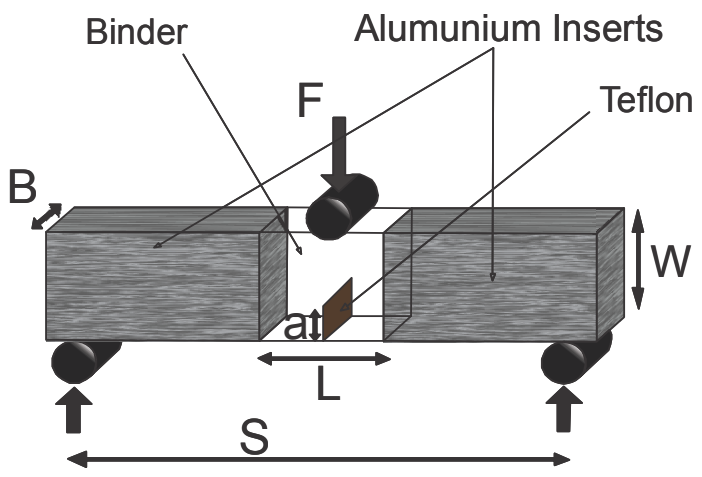

Figure 1. Test sample geometry

ent asphalt binders were tested in three points bending at temperatures between $-5^{\circ} \mathrm{C}$ and $-15^{\circ} \mathrm{C}$ and compared to the critical temperatures obtained for BBR tests.

\section{EXPERIMENTAL DESIGN}

\subsection{Asphalt Binders}

Eight different asphalt binders were used in this study. These asphalts were selected according to the origin of the crude petroleum, the manufacturing process, and the type of modifiers used. Three direct-distilled asphalts of different origins $\left(\mathrm{B}_{1}, \mathrm{~B}_{2}\right.$ and $\left.\mathrm{B}_{3}\right)$ and a semi-blown asphalt $\left(\mathrm{B}_{4}\right)$ with the same $35 / 50$ penetration (standard NF EN 12591) were used. $B_{1}$ asphalt was modified using four types of additives: Sasobit ${ }^{\circledR}$ paraffin wax $\left(\mathrm{B}_{\mathrm{M} 1}\right)$, polyphosphoric acid at $105-118 \%\left(\mathrm{~B}_{\mathrm{M} 2}\right)$, crosslinker-free SBS polymer $\left(\mathrm{B}_{\mathrm{M} 3}\right)$ and crosslinked SBS polymer $\left(\mathrm{B}_{\mathrm{M} 4}\right)$.

Aged materials were obtained from the eight previously presented asphalt binders by a process idealized by Migliori and Corté (1998). Those authors have shown that the commonly used laboratory procedures to induce aging (1h in rolling thin film oven test - RTFOT - and 20h in paving aging vessel - PAV) produce physical effects, e. g. increase in asphaltenes content and in the rigidity obtained in BBR and complex modulus tests, equivalent to those obtained when conducting aging for $25 \mathrm{~h}$ in PAV. So, aging process used in this work was to maintain materials at $100^{\circ} \mathrm{C}$ and 2.1 MPa during $24 \mathrm{~h}$.

\subsection{Measurement of complex modulus}

Asphalt is a viscoelastic material, so its properties are dependent on its thermal and loading histories. The complex modulus test determines intrinsic characteristics of asphalt materials under small deformation conditions (complex modulus, phase difference). The complex modulus tests were performed applying a controlled strain $\varepsilon^{*}(\mathrm{t}, \omega, \theta)$ (time, frequency, temperature) to a test specimen and recording the stress response $\sigma^{*}(t, \omega, \theta)$ under different temperatures and frequencies. Depending on the temperature, the test is performed in tensile-compression $\left(\leq 20^{\circ} \mathrm{C}\right)$ or annular shear $\left(\geq 20^{\circ} \mathrm{C}\right)$.

\subsection{Bending Beam Rheometer}

The Bending Beam Rheometer (BBR) is a tool to perform low-temperature creep tests. Tests are carried out at different temperatures $\left(-24,-18\right.$ and $-12^{\circ} \mathrm{C}$ ) (AASHTO T 31302). Asphalt beams are prepared in an aluminum mold with 24 hours of storage for each sample. The beams are immersed in a cold bath. After one hour at the test temperature, a constant load equivalent to $100 \mathrm{~g}$ is applied for 240 seconds to the prismatic beam supported at both ends by stainless steel cylinders (set $102 \mathrm{~mm}$ apart). Center point deflection is measured continuously. By using a linear interpolation, these tests give a measure of creep stiffness at any moment and any temperature. Different parameters can be calculated with BBR results and their definition is indicated in Table 1.

\subsection{Three Points Bending Test (TPBT)}

For this research the TPBT on pre-notched asphalt beam was adapted to bituminous binders. The test specimen was a piece of pre-notched asphalt extended by two aluminum extender inserts (Figure 1). The aluminum inserts were employed to reduce the quantity of asphalt and make the bottom supports less sensitive to the indentation phenomenon (Chailleux et al., 2008). The same authors have shown that the inserts presence may influence the mechanical fields at the pit of the notch, but for L longer than $40 \mathrm{~mm}$, the aluminum extenders had no mechanical influence around the crack.

The test samples were produced by molding at $150^{\circ} \mathrm{C}$ around two $25 \mu \mathrm{m}$-thick Teflon sheets bonded with mineral grease to form a reproducible pre-notch. Before adding the asphalt, the film is tightened to produce a pre-notch as straight as possible and thus trigger mode I fracture (opening).

The test was conducted with a rate displacement of $0.6 \mathrm{~mm} / \mathrm{min}$. A Zwick tensile-compression tester machine was used. The test was conducted in a potassium acetate bath able to carry the test temperature down to $-30^{\circ} \mathrm{C}$. 


\section{NOTIONS OF FRACTURE MECHANICS AND LINEAR VISCOELASTICITY}

\subsection{Determination of $S(t)$ for $B B R$ tests}

To simulate BBR tests, one needs to obtain analytical expressions representing linear viscoelastic mechanical behavior. This can be done by using mechanical models fitted to experimental data. The model used in this paper is the classic generalized Maxwell model. The relaxation curve obtained for this model can be mathematically expressed in Prony series terms:

$$
E(t)=\frac{\sigma(t)}{\varepsilon}=E_{0}+\sum_{i=1}^{n} E_{i} \cdot e^{\left(-t / \tau_{i}\right)}, \text { for } \mathrm{t}>0
$$

The Maxwell model parameters were obtained using a non-linear optimization of the Cost function (square differences between model prediction and test result) defined for the Complex Modulus master curve as described by Hammoum et al. (2009). The computation of Maxwell model prediction is done by Equations 2 and 3 .

$$
\begin{gathered}
E 1=E_{0}+\sum_{i}^{n} E_{i} \cdot \frac{\left(\omega \tau_{i}\right)^{2}}{1+\left(\omega \tau_{i}\right)^{2}} \\
E 2=\sum_{i}^{n} E_{i} \cdot \frac{\left(\omega \tau_{i}\right)}{1+\left(\omega \tau_{i}\right)^{2}}
\end{gathered}
$$

Knowing the relaxation curve makes it possible to distinguish stress history from strain history using the viscoelastic constitutive law described by the convolution integral:

$$
\sigma(t)=\int_{0}^{t} E(t-u) \cdot \frac{\partial \varepsilon}{\partial u} d u
$$

Equation 2 is calculated numerically running a discretizing step with respect to the time considered, i.e. $t=\left[t_{1}, \ldots t_{k}\right.$ $\left.\ldots, \mathrm{t}_{\mathrm{N}}\right], \sigma(\mathrm{t})=\left[\sigma_{1}\left(\mathrm{t}_{1}\right), \ldots \sigma_{\mathrm{k}}\left(\mathrm{t}_{\mathrm{k}}\right) \ldots \sigma_{\mathrm{N}}\left(\mathrm{t}_{\mathrm{N}}\right)\right]$ and $\varepsilon(\mathrm{t})=\left[\varepsilon_{1}\left(\mathrm{t}_{1}\right)\right.$, $\left.\ldots \varepsilon_{\mathrm{k}}\left(\mathrm{t}_{\mathrm{k}}\right) \ldots \varepsilon_{\mathrm{N}}\left(\mathrm{t}_{\mathrm{N}}\right)\right]$. Equation 4 , discretized in time steps $\mathrm{t}_{\mathrm{i}}$, gives an approximation in the following form:

$$
\sigma\left(t_{k}\right) \approx \sum_{i=1}^{k} \dot{\varepsilon}_{i} \cdot \int_{t_{i-1}}^{t_{i}} E\left(t_{k}-u\right) \delta u=\sum_{i=1}^{k} \dot{\varepsilon}_{i} \cdot a_{i k}
$$

in which the $\mathrm{a}_{\mathrm{ik}}$ values are calculated as follows:

$$
\begin{aligned}
& a_{i k}=\int_{t_{i-1}}^{t_{i}} E\left(t_{k}-u\right) \delta u=\int_{t_{i-1}}^{t_{i}}\left(E_{0}+\sum_{j=1}^{m} E_{j} \cdot \exp \left(\frac{-\left(t_{k}-u\right)}{\tau_{j}}\right)\right) \delta u \\
& a_{i k}=E_{0}\left(t_{i}-t_{i-1}\right)+\sum_{j=1}^{m} E_{j} \tau_{j}\left(\exp \left(\frac{t_{i}-t_{k}}{\tau_{j}}\right)-\exp \left(\frac{t_{i-1}-t_{k}}{\tau_{j}}\right)\right)
\end{aligned}
$$

It is then necessary to verify that this new numerical implementation fits the measured values from which the model was derived (see Figure 2).

In order to obtain the strain history from the stresses, the following recursive principle is used:

$$
\begin{gathered}
\dot{\varepsilon}_{1}=\frac{\sigma_{1}}{a_{11}} \\
\dot{\varepsilon}_{k}=\frac{\sigma_{k}-\sum_{i=1}^{k-1} \dot{\varepsilon}_{i} \cdot a_{i k}}{a_{k k}} \\
\varepsilon_{k+1}=\dot{\varepsilon}_{k} \cdot\left(t_{k+1}-t_{k}\right)+\varepsilon_{k}
\end{gathered}
$$

Then, one can obtain the numerically calculated secant modulus:

$$
S_{k}=\frac{\sigma_{k}}{\varepsilon_{k}}
$$

\subsection{Determination of stress and crack opening intensity factors}

Given that the three points bending fracture test is conducted in mode I (opening), the equations and calculations used in this paper are only valid for mode-I cracking.

\subsubsection{Key principles in fracture mechanics}

In the context of linear elastic fracture mechanics, the stress and displacement fields at the crack tip in elastic media can be described by a single parameter that is intrinsic to the material: the stress intensity factor (equations 12 and 13).

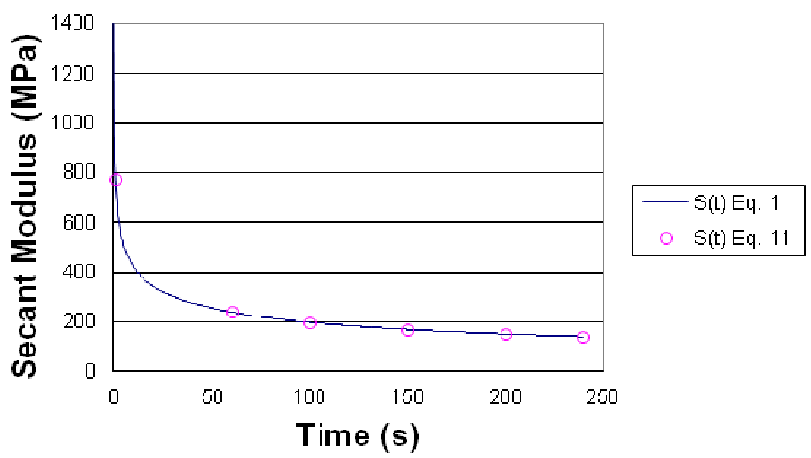

Figure 2. Verification of the numerical implementation of the Prony series simulating the response to a creep test for $\mathrm{B}_{1}$ 


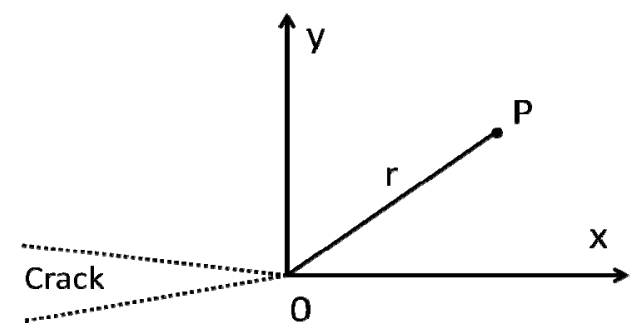

Figure 3. Notations for a planar crack

Figure 3 illustrates a planar coordinate system used to describe stress and displacement fields around a crack tip. The stress intensity factor can be calculated from either the crack opening or the stress field at the crack tip. The next section proposes an application of this theory to a viscoelastic material.

$$
\begin{gathered}
\sigma_{y y}^{\theta}=\frac{K^{\sigma}}{\sqrt{2 \cdot \pi \cdot r}} \cos \frac{\theta}{2}\left(1+\sin \frac{\theta}{2} \cdot \sin \frac{3 \theta}{2}\right)(12) \\
u_{y}^{\theta}=\frac{K^{\sigma} \cdot(1+v)}{E} \sqrt{\frac{r}{2 \pi}} \sin \frac{\theta}{2}\left(\kappa+1-2 \cos ^{2} \frac{\theta}{2}\right)
\end{gathered}
$$

where,

$\sigma_{y y}^{\theta}:$ crack opening stress;

$u_{y}^{\theta}:$ crack opening strain;

$v$ : Poisson's ratio;

E: Young's modulus;

$\kappa=3-4 \cdot v$ in planar deformation and

$\kappa=(3-v) /(1+v)$ in planar stress.

\subsubsection{Stress intensity factor in viscoelasticity}

In this section, the expression of the stress intensity factor $\mathrm{K}^{\sigma}(\mathrm{t})$ is determined for a linear viscoelastic material at constant Poisson's ratio under force $\mathrm{F}(\mathrm{t})$ and displacement $\mathrm{d}(\mathrm{t})$. $\mathrm{K}_{\mathrm{e}}{ }^{\sigma}$ is the stress intensity factor and $\mathrm{R}_{\mathrm{e}}$ is the geometric stiffness of an elastic material at unit displacement $d_{e}=1$ and unit Young's modulus $\mathrm{E}_{\mathrm{e}}=1$. The stress and displacement fields in the vicinity of the crack under these conditions are written:

$$
\begin{aligned}
& \sigma_{e}(x) \approx f_{\text {gén }}(x) K_{e}^{\sigma} \\
& u_{e}(x) \approx g_{\text {gén }}(x) K_{e}^{\sigma}
\end{aligned}
$$

where,

$f_{\text {gen }}$ : 'generic form' functions of the stress; e

$g_{g e n}$ : displacement distributions at the crack base.

The stress and displacement fields in the vicinity of the crack under identical geometry but for a viscoelastic material can be written:

$$
\begin{gathered}
\sigma(x, t)=\sigma_{e}(x) \frac{F(t)}{R_{e}} \\
u(x, t)=u_{e}(x) d(t)
\end{gathered}
$$

$$
F(t)=R_{e} S(t) d(t)
$$

This leads to:

$$
\begin{gathered}
\sigma(x, t) \approx f_{\text {gén }}(x) K_{e}^{\sigma} \frac{F(t)}{R_{e}} \\
u(x, t) \approx g_{g e ́ n}(x) K_{e}^{\sigma} \frac{F(t)}{R_{e} S(t)}
\end{gathered}
$$

The expression of the stress and displacement fields in the vicinity of a crack in a viscoelastic material is therefore:

$$
\begin{gathered}
\sigma(x, t) \approx f_{\text {gén }}(x) K^{\sigma}(t) \\
u(x, t) \approx g_{\text {gén }}(x) \frac{K^{\sigma}(t)}{S(t)} \\
K^{\sigma}(t)=\frac{K_{e}^{\sigma}}{R_{e}} F(t)=K_{e}^{\sigma} S(t) d(t)
\end{gathered}
$$

It thus appears that $\mathrm{K}^{\sigma}(\mathrm{t})$ can be calculated from $\mathrm{K}_{\mathrm{e}}{ }^{\sigma}$ and the resulting force, as well as from $\mathrm{K}_{\mathrm{e}}{ }^{\varepsilon}$ and the displacement, although in the latter case, the secant modulus $\mathrm{S}(\mathrm{t})$ has to be known. Section 3.2.4 describes a finite elements calculation method for determining $\mathrm{K}_{\mathrm{e}}$.

\subsubsection{Crack opening intensity factor $\left(K^{\varepsilon}\right)$}

Viscoelastic materials do not present direct proportionality between force applied and form of the crack front. In addition to describing the stress field at the crack base, $\mathrm{K}^{\sigma}(\mathrm{t})$, it is also useful to find a purely geometric criterion describing crack form. Therefore, the idea of crack opening intensity factor $\mathrm{K}^{\varepsilon}(\mathrm{t})$, as previously proposed in Chazal and Dubois (2001) and Dubois and Petit (2005), is used (equation 24). These authors assert that it is possible to determine the strain energy release rate, $\mathrm{G}(\mathrm{t})$, of a viscoelastic material (equation 25) from $\mathrm{K}^{\sigma}$ and $\mathrm{K}^{\varepsilon}$.

$$
\begin{aligned}
& u_{y}(t)=\sqrt{\frac{r}{2 \pi}} \cdot K^{\varepsilon}(t) \\
& G(t)=\frac{K^{\sigma}(t) \cdot K^{\varepsilon}(t)}{8}
\end{aligned}
$$

Introducing secant modulus, $\mathrm{S}(\mathrm{t})=\sigma(\mathrm{t}) / \varepsilon(\mathrm{t})$, it gives: 
As the test is conducted at set rate displacement speed, the crack form is known at every moment. This means that $\mathrm{K}^{\varepsilon}(\mathrm{t})$ can be calculated from $\mathrm{d}(\mathrm{t})$ according to equation 26 .

$$
K^{\varepsilon}(t)=K_{e}^{\varepsilon} \cdot d(t)
$$

\subsubsection{Finite element method for determining intensity fac- tors $K_{e}{ }^{\sigma}$ and $K_{e}{ }^{\varepsilon}$}

Equations 12 and 13 are only the first term of a Taylor series. The displacement fields can more generally be written as in equations 27 and 28.

$$
\begin{gathered}
u_{y}^{\theta}(r)=K^{\sigma} \cdot \frac{(1+v)}{E} \cdot \sqrt{\frac{r}{2 \pi}} \cdot g_{y}^{1}(\theta)+\mathrm{O}(\sqrt{r}) \\
u_{y}(r)=\sqrt{\frac{r}{2 \pi}} \cdot K^{\varepsilon}+\mathrm{O}(\sqrt{r})
\end{gathered}
$$

Consequently, the term $\mathrm{O}(\sqrt{r})$ has to be integrated as soon as the displacement field is calculated far from the crack tip. Therefore, a calculation integrating a larger zone around the crack tip needs to include the first order term. For a calculation running along the crack plane $(\theta=\pi)$, this gives equations 29 and 30 (Chailleux et al., 2006).

$$
\begin{aligned}
& u_{y}(x)=\frac{2}{\pi} \cdot \frac{K^{\sigma}}{E} \cdot \sqrt{2 \cdot \pi \cdot x}+A_{2} \cdot|x|^{3 / 2} \\
& u_{y}(x)=\frac{2}{\pi} \cdot K^{\varepsilon} \cdot \sqrt{2 \cdot \pi \cdot x}+A_{3} \cdot|x|^{3 / 2}
\end{aligned}
$$

Working with a finite elements method numerical simulation of the TPBT, displacement $\mathrm{u}_{\mathrm{y}}$ of the crack mouth is calculated theoretically for a deflection $\mathrm{d}=1 \mathrm{~m}$ and a modulus $\mathrm{E}=1 \mathrm{~Pa}$. It thus becomes apparent that equations 29 and 30 are equivalent and that $\mathrm{K}_{\mathrm{e}}{ }^{\sigma}$ and $\mathrm{K}_{\mathrm{e}}{ }^{\varepsilon}$ are equal. This means that only one of these two parameters, i.e. $\mathrm{K}_{\mathrm{e}}{ }^{\sigma}$, needs to be determined by finite elements calculus. Then, the $\mathrm{K}_{\mathrm{e}}{ }^{\sigma}$ coefficient can thus be reverse-analyzed by deducing the adjustment to the analytical formula for $\mathrm{u}_{\mathrm{y}}$ on the numerical calculation of this same displacement field.

\subsubsection{Numerical simulation of the three points bending test}

This study used two finite element codes: CESAR-LCPC and Cast3M. Given that the structure is symmetrical, only half the test specimen was modeled. The calculations are performed in planar stress conditions. The sample matrix is finer-grained around the crack (and different for the two codes). Boundary conditions are simulated by barring horizontal displacement of nodes situated along the axial symmetries above the crack and barring vertical displacement of the node corresponding to the sample support surface. Top-die displacement is modeled via a set displacement value on the node situated under the die. The properties of the two materials used for the finite element calculation are given in Table 2 .

\subsubsection{Determination of $K_{e}^{\sigma}$ by reverse analysis}

$\mathrm{K}^{\sigma}$ and $\mathrm{A}_{2}$ in equation 29 are determined by adjusting the analytical formulation of the finite-elements numerical results. This is achieved by selecting a $2 \mathrm{~mm}$ zone leading from the crack tip and determining the parameters via an optimization procedure based on the least squares method. As illustrated in Figure 4, the analytical solution matches the solution obtained by finite element analysis. Then it becomes possible to determine the $\mathrm{R}_{\mathrm{e}}$ parameter of equation 23 (Table 3).

\section{RESULTS}

Finite elements modeling was used to determine the mathematical expression of stress intensity and crack opening intensity factors for a viscoelastic material under set rate forced displacement conditions. The results obtained (stress at fracture, elongation at fracture) make it possible to calcu-

Table 2. Values used for the finite element calculations

\begin{tabular}{llllllllll}
\hline $\boldsymbol{B}(\mathbf{m m})$ & $\boldsymbol{S}(\mathbf{m m})$ & $\boldsymbol{W}(\mathbf{m m})$ & $\boldsymbol{L}(\mathbf{m m})$ & $\boldsymbol{a}(\mathbf{m m})$ & $\boldsymbol{d}(\mathbf{m})$ & $\boldsymbol{E}_{\text {bit }}(\boldsymbol{P a})$ & $\boldsymbol{v}_{\text {bit }}$ & $\boldsymbol{E}_{\text {alu }}(\boldsymbol{G P a})$ & $\boldsymbol{v}_{\text {alu }}$ \\
\hline 12.5 & 100 & 25 & 40 & 5 & 1 & 1 & 0.35 & 73 \\
\hline
\end{tabular}

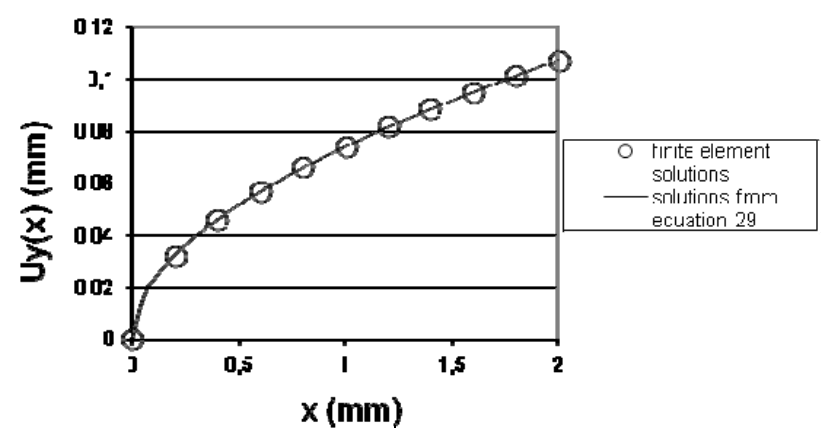

Figure 4. Displacement of the crack mouth under loading. Analytical solution (equation 29) and numerical solution (CESAR-LCPC)

Table 3. Values obtained for the finite element calculations

\begin{tabular}{lll}
\hline & CESAR-LCPC & Cast3m (SIF modulus) \\
\hline $\mathrm{K}_{\mathrm{e}}{ }^{\sigma}(\mathrm{m}-0.5)$ & 1.4426 & 1.4570 \\
$\mathrm{R}_{\mathrm{e}}(\mathrm{m})$ & $0.63510-3$ & $0.64010-3$ \\
\hline
\end{tabular}


late critical factors according to the temperature for each asphalt binder of the study. The values of these critical factors are means of three tests of three points bending.

\subsection{BBR Modeling and Comparison to Experimental Results}

By the method described in section 3.1, it is possible to simulate BBR tests and to calculate the simulated indicators described in section 2.3. based on the Maxwell model fit to complex modulus data. Experimental and modeled results for all asphalt binders and their aged products are shown in Figures 5 and 6. Despite the mean difference between model prediction and experimental results $\left(2.6^{\circ} \mathrm{C}\right.$ for $\mathrm{T}_{300 \mathrm{MPa}}$ and $1.1^{\circ} \mathrm{C}$ for $\mathrm{T}_{\text {Crit }}$ ), the determination coefficients obtained between them were high, as it can be seen in Fig- ures 5 and 6.

\subsection{Results of the Three Points Bending Test}

For all asphalts of the study, their behavior (stress, elongation) changes between $-15^{\circ} \mathrm{C}$ and $-3^{\circ} \mathrm{C}$. As an example, the time course of the Force $=\mathrm{f}$ (displacement) curve according to different temperatures for $\mathrm{B}_{\mathrm{M} 2}$ is plotted on Figure 7. It is to be noted that, for every asphalt binder, there is a limit cracking temperature (LCT). This implies that after a certain temperature, which depends on the asphalt binder, there is no more cracking. This temperature is determined with an accuracy of $1{ }^{\circ} \mathrm{C}$. So, critical stress intensity factor, critical crack opening intensity factor and critical strain energy release rate are determined between $-15^{\circ} \mathrm{C}$ and their LCT.

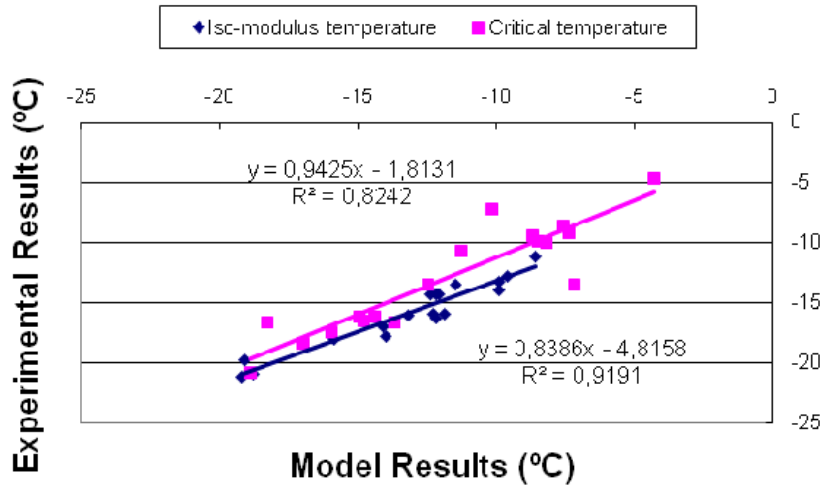

Figure 5. Correlation between experimental and simulated BBR limit temperatures

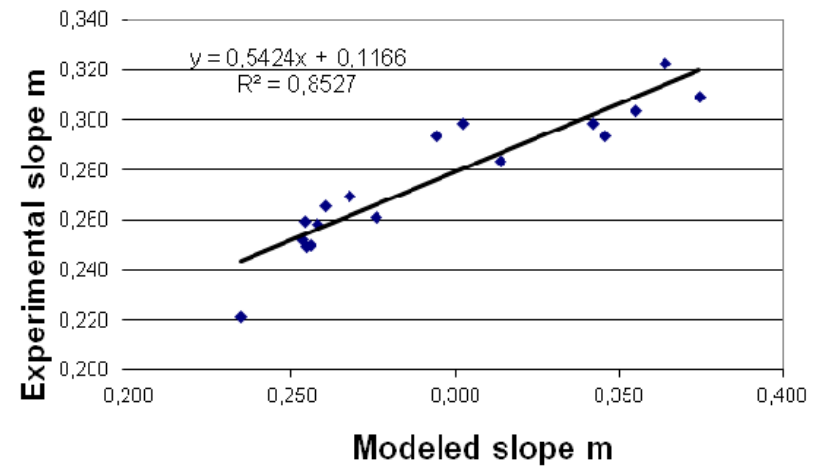

Figure 6. Correlation between experimental and simulated BBR slope $\mathrm{m}$

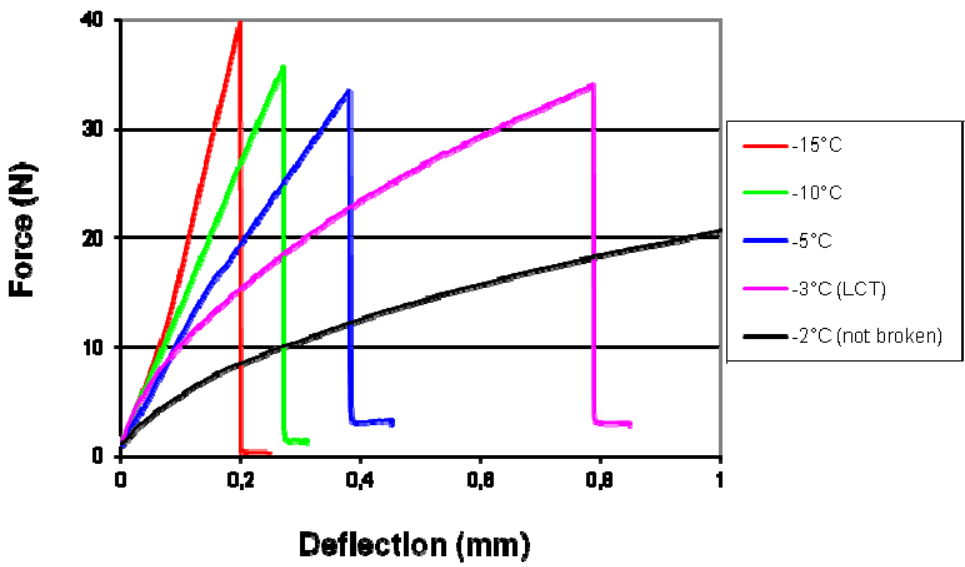

Figure 7. Curve plotting three points bending fracture tests for BM2 at different temperatures 


\subsection{Calculation of the Critical Stress Intensity Factor $\left(\mathrm{K}_{\mathrm{c}}{ }^{\sigma}\right)$}

The critical stress intensity factor is first calculated from force at fracture (Figure 8). When temperature is close to $5^{\circ} \mathrm{C}, \mathrm{K}_{\mathrm{C}}{ }^{\sigma}$ remains the same, regardless of asphalt type, although at the temperature of $-15^{\circ} \mathrm{C}$, this critical stress intensity factor appears to be highly dependent on the type of asphalt. It has to be noted that $\mathrm{B}_{4}$ and $\mathrm{B}_{\mathrm{M} 4}$ have the lowest LCTs $\left(-8^{\circ} \mathrm{C}\right)$ and seem to have a cracking behavior different from the others.

\subsection{Calculation of the Critical Crack Opening Intensity Factor $\left(\mathrm{K}_{\mathrm{C}}{ }^{\varepsilon}\right)$}

Figure 9 illustrates the $\mathrm{K}_{\mathrm{C}}{ }^{\varepsilon}$ curves according to the temperature for the asphalts studied. As temperature increases, the critical crack opening intensity factor also increases. Note that in contrast to what happens to $\mathrm{K}_{\mathrm{C}}{ }^{\sigma}, \mathrm{K}_{\mathrm{C}}{ }^{\varepsilon}$ evolutions are monotonic regardless of the temperature. $\mathrm{B}_{4}$ and $\mathrm{B}_{3}$ have the highest $\mathrm{K}_{\mathrm{C}}{ }^{\varepsilon}$. No link can be found between $\mathrm{K}_{\mathrm{C}}{ }^{\varepsilon}$ and LCT. Indeed, LCT values for $\mathrm{B}_{\mathrm{M} 3}$ and $\mathrm{B}_{\mathrm{M} 4}$ are between $\mathrm{B}_{4}$ and $\mathrm{B}_{3}$ whereas their $\mathrm{K}_{\mathrm{C}}{ }^{\varepsilon}$ are lower than $\mathrm{B}_{4}$ and $\mathrm{B}_{3}$.

\subsection{Calculation of Critical Strain Energy Release Rate $\left(G_{I C}\right)$}

The critical strain energy release rate is calculated with equation 25 when time assumes the instant of rupture. Figure 10 shows that $\mathrm{G}_{\mathrm{IC}}$ curves according to temperature follow the same pattern as $\mathrm{K}_{\mathrm{C}}{ }^{\varepsilon}$ curves. This would appear logical, given that the $\mathrm{K}_{\mathrm{C}}{ }^{\sigma}$ values for the test asphalts are simi- lar within the temperature range studied.

\section{DISCUSSION AND COMPARISON WITH BBR}

LCT and $\mathrm{G}_{\mathrm{IC}}$ will be used together and compared to BBR critical temperature and Iso-modulus (300MPa) temperature. The LCT will be considered as the main cracking characteristic obtained by three points bending. However, if some samples have the same limit cracking temperature, we will use $\mathrm{G}_{\mathrm{IC}}$ values in order to establish a ranking between asphalts.

Results from three points bending and bending beam rheometer are presented in Table 4. Ranking of asphalts binder are not similar for TPBT and BBR. Polymers modified asphalts have a lower LCT than $\mathrm{B}_{2}$ with TPBT results but have a higher iso-modulus temperature and critical temperature than $\mathrm{B}_{2}$. Moreover, the crosslinked polymer modified asphalt has a lower LCT than crosslinker-free contrary to results from BBR. It seems more logical that the use of a crosslinker improves asphalt resistance properties.

\section{CONCLUSIONS}

This study has established a framework for applying fracture mechanics-based criteria to a three points bending fracture test on asphalt binders. The results show that stress and crack opening criteria are discriminatory factors across different temperature ranges, regardless of the asphalts tested. BBR critical temperatures were almost the same (between -

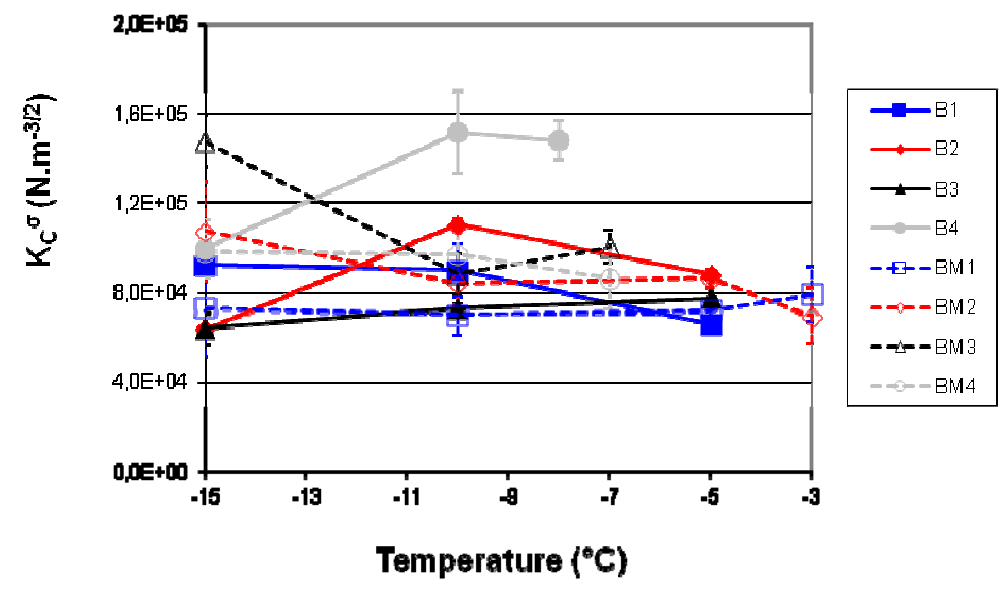

Figure 8. Asphalt toughness curves according to temperature calculated via stress at fracture

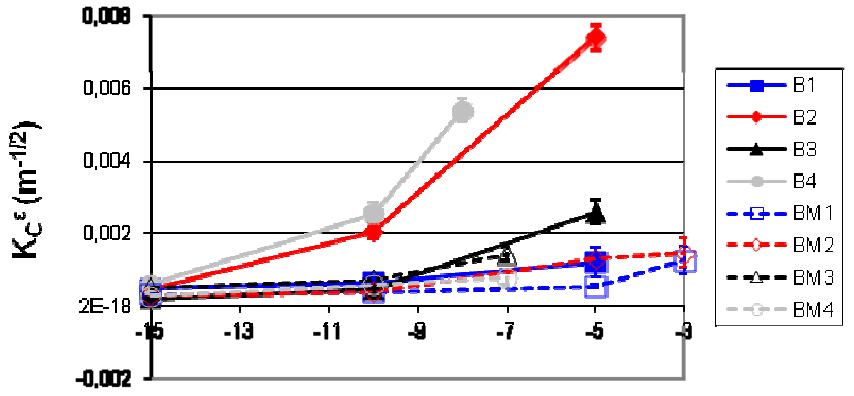

Temperature $\left({ }^{\circ} \mathrm{C}\right)$

Figure 9. Critical crack opening intensity factor curves for the tested asphalts according to temperature 


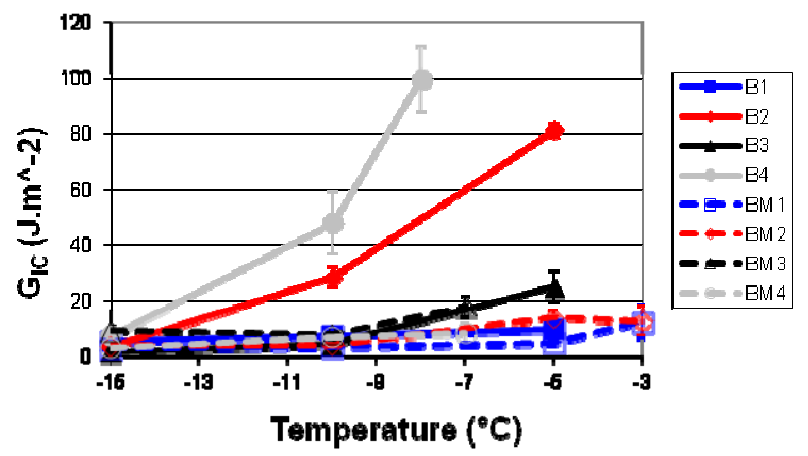

Figure 10. Critical strain energy release rate curves for the tested asphalts according to temperature

Table 4. Comparison between three points bending and BBR results

\begin{tabular}{|c|c|c|c|c|}
\hline & Limit cracking temperature $\left({ }^{\circ} \mathrm{C}\right)$ & $G I C(J . m-2)$ & Iso-modulus $(300 \mathrm{MPa})$ temperature $\left({ }^{\circ} \mathrm{C}\right)$ & Critical temperature $\left({ }^{\circ} \mathrm{C}\right)$ \\
\hline B1 & -5 & 9.9 & -15.9 & -16.2 \\
\hline B2 & -5 & 81.6 & -20.9 & -20.8 \\
\hline B3 & -5 & 25.0 & -16.0 & -17.3 \\
\hline B4 & -8 & 99.7 & -21.1 & -18.3 \\
\hline BM1 & -3 & 12.5 & -13.9 & -13.4 \\
\hline BM2 & -3 & 12.8 & -16.2 & -16.5 \\
\hline BM3 & -7 & 18.0 & -17.7 & -16.6 \\
\hline BM4 & -8 & 8.4 & -17.0 & -16.5 \\
\hline
\end{tabular}

$16^{\circ} \mathrm{C}$ and $\left.-17^{\circ} \mathrm{C}\right)$ for the modified binders $\left(\mathrm{B}_{\mathrm{M} 2}, \mathrm{~B}_{\mathrm{M} 3}\right.$ and $\left.\mathrm{B}_{\mathrm{M} 4}\right)$ and for the original conventional one $\left(\mathrm{B}_{\mathrm{M} 1}\right)$. Only $\mathrm{B}_{\mathrm{M} 1}$ had significantly different critical temperature, presenting, according to BBR, lower performance At low temperature, when the material is in a quasi-elastic state, the critical crack opening factor is constant $\left(\mathrm{K}_{\mathrm{C}}{ }^{\varepsilon} \sim 2 \cdot 10^{-4} \mathrm{~m}^{-1 / 2}\right)$. On the other hand, at a higher temperature, the critical crack opening factor runs from $2.10^{-4} \mathrm{~m}^{-1 / 2}$ to $8.10^{-3} \mathrm{~m}^{-1 / 2}$. In contrast, the critical stress intensity factor does not appear to depend on the asphalt type at high temperatures $\left(\mathrm{K}_{\mathrm{C}}{ }^{\sigma} \sim 8.10^{4} \mathrm{~N} . \mathrm{m}^{-}\right.$ ${ }^{3 / 2}$ ), except for $\mathrm{B} 4$, and at low temperatures it runs from $6.10^{4} \mathrm{~N} \cdot \mathrm{m}^{-3 / 2}$ to $16.10^{4} \mathrm{~N} \cdot \mathrm{m}^{-3 / 2}$. The greater variability of $\mathrm{K}_{\mathrm{C}}{ }^{8}$ compared to $\mathrm{K}_{\mathrm{C}}{ }^{\sigma}$ means that the critical strain energy release rates calculated using the Dubois formula (Dubois and Petit, 2005) appear to be discriminant at high temperatures. Moreover, a new criterion is introduced: the LCT which corresponds to the last temperature where there is crack propagation using the presented TPBT.

With the modeling procedure presented in this paper, BBR indicators $\left(\mathrm{T}_{300 \mathrm{MPa}}, \mathrm{m}\right.$-value and $\left.\mathrm{T}_{\text {Crit }}\right)$ can be obtained from complex modulus data (master curve) assuming a linear viscoelastic model. Asphalt binders can be ranked using these criteria only simulating BBR tests with a model fitted to complex modulus data instead of performing those tests. This agrees with the results obtained by Olard (2009), who obtained creep compliance from complex modulus through empirical formulae.

BBR tests allow the estimation of low temperature specifications, but they are only based on materials' linear viscoelastic properties. Higher stiffness induces higher stresses in the material under loading, but this is not the only factor determining crack growth. This phenomenon is associated to material toughness. Concerning cracking resistance ranking, three points bending tests and bending beam rheometer give different results. Results with asphalt modified by crosslinked SBS and crosslinker-free SBS seem to show that limit cracking temperature is a reliable property of low temperature asphalt cracking.

\section{ACKNOWLEDGEMENTS}

The authors would like to thank the enterprise Total and the LCPC for their researching support and cooperation.

\section{REFERENCES}

AASHTO T 303 (2002) Standard test method for determining the flexural creep stiffness of asphalt binder using the Bending Beam Rheometer (BBR), T 313-02, American Association of State Highway and Transportation Officials, AASHTO, Washington D. C.

NF EN 12591 (1999) Bitumen and bituminous binders - Specifications for paving grade bitumen. European Standard. Bruxels.

Chailleux E.; D. Hamon and V. Mouillet (2006) Determination of the low temperature bitumen cracking properties: fracture mechanics principle applied to a three points bending test using a nonhomogeneous Geometry, 10th International Conference on Asphalt Pavements, Québec, Canada, v. 1, p. 419-428.

Chailleux, E.; G. Ramond; C. Such and de la Roche, C. (2006) A mathematical-based master-curve construction method applied to complex modulus of bituminous materials. Road Materials and Pavement Design. EATA, p 75-92.

Chailleux E.; V. Mouillet; E. Scholten; T. Blomberg and S. Dreessen (2008) Evaluation of the three-point bending test as a tool to qualify the low-temperature behaviour of bituminous binder. Eurasphalt \& Eurobitume congress, Copenhagen, Danemark.

Chazal C. and F. Dubois (2001) A new incremental formulation in the time domain of crack initiation in an orthotropic linearly viscoelastic solid, Mechanics of Time-Dependent Materials, v. 5, p. 3-21.

Dubois F. and C. Petit (2005) Modeling of the crack growth initiation in viscoelastic media by the G0v-integral. Engineering Fracture Mechanics, v. 72, n. 18, p. 2821-2836.

Hammoum, F.; E. Chailleux; H-N. Nguyen; A. Erhlacher; J-M Piau and D. Bodin (2009) Experimental and Numerical Analysis of Crack Initiation and Growth in Thin Film. Road Materials and Pavement Design. EATA, p. 39-61.

Lee N. K. and S. A. M. Hesp (1994) Low-temperature fracture toughness of polyethylene-modified asphalt binders. Transportation Research Record, v.1436, p. 54-59.

Migliori, F. and J-F Corté (1998) Comparative study of RTFOT and PAV Aging Simulation Laboratory Tests. Annual Meeting of the Trans- 
portation Research Board No 77, Washington D. C., n. 1638, p. $56-63$.

Morrison G. R., N. K. Lee and S. A. M. Hesp (1994) Chlorinated polyolefins for asphalt binder modification. Journal of Applied Polymer Science, v. 54, p. 231-240.

Olard, F. (2009) Prédiction des résultats des tests de fluage BBR à partir des résultats de module complexe. Bulletin des Laboratoires des Ponts et Chaussées. n. 252-53, p. 3-15.

Ponniah J. E. and S. A. M. Hesp (1996) Use of fracture energy in performance-based specifications of asphalt binders. Proceedings, Canadian Technical Asphalt Association, v. 41, p. 127-144. 